Instructions for authors, subscriptions and further details:

http://brac.hipatiapress.com

\title{
De la Originalidad y sus Desplazamientos Artísticos. El Artefacto de la Copia y lo Abominable de lo Original
}

Carles Méndez Llopis ${ }^{1}$

1) Universidad Autónoma de Ciudad Juárez. México

Date of publication: October 3rd, 2015

Edition period: October 2015 - February 2016

To cite this article: Méndez Llopis, C. (2015). De la originalidad y sus desplazamientos artísticos. El artefacto de la copia y lo abominable de lo original. Barcelona, Research, Art, Creation, 3(3), 256-276. doi: 10.17583/ brac.2015.1567

To link this article: http://dx.doi.org/10.17583/brac.2015.1567

\section{PLEASE SCROLL DOWN FOR ARTICLE}

The terms and conditions of use, except where otherwise noted, are related to the Open Journal System and to Creative Commons Attribution License (CCBY). The indication must be expressly stated when necessary. 
BRAC - Barcelona Research Art Creation. Vol. 3 No. 3, October 2015, pp. 256-276

\section{Originality and Artistic Displacements. The Copy's Artifact and the Abominable of the Original}

Carles Méndez Llopis

Autonomous University of Ciudad Juarez

(Received: 9 June 2015; Accepted: 9 September 2015; Published: 3 October 2015)

\section{Abstract}

The heterogeneity and complexity of symbolic production and the current artistic creation, invites the scrutiny and review of inherited parameters in the cultural field. The various crises traversed by the field and those that still serve as the discussion centers, generate conceptual depletions about the axioms that distance themselves from the generation of contemporary knowledge. In this sense, this paper analyzes the ideal of originality -disseminated especially from the romantic perspective- to understand and limit its tentacles, inserting them into the current discipline's selfreflection, in the new artistic structuring that comes unfolding since the sixties, and the digitalization and virtualization scenarios that we live in today. All this determines not only different strategies in the relations between the areas of production, reception and consumption, but also connections between concepts such as original and copy that had not been visited until this time. What follows is therefore a theoretical approach to the necessary reformulation of monolithic standards in the arts, a critique of originality.

Keywords: Originality, copy, multiple art, hyperreproducibility 
BRAC - Barcelona Research Art Creation. Vol. 3 No. 3, October 2015, pp. 256-276

\section{De la Originalidad y sus Desplazamientos Artísticos. El Artefacto de la Copia y lo Abominable de lo Original}

Carles Méndez Llopis

Universidad Autónoma de Ciudad Juárez

(Recibido: 9 Junio 2015; Aceptado: 9 Septiembre 2015; Publicado: 3 Octubre 2015)

\section{Resumen}

La heterogeneidad y complejidad en la producción simbólica y la creación artística actual invita al escrutinio y reconsideración de parámetros heredados en el campo cultural. Las diversas crisis atravesadas en el ámbito, así como aquellas que siguen ubicándose como centros de la discusión, generan agotamientos conceptuales sobre axiomas que se distancian de la generación del conocimiento contemporánea. En este sentido, el presente texto analiza el ideal de originalidad-diseminado sobre todo desde la perspectiva romántica- para comprender y acotar sus tentáculos, insertándolos en la autorreflexión disciplinar del presente, en las nuevas estructuraciones artísticas que vienen desenvolviéndose desde los años sesenta, así como en los escenarios de digitalización y virtualización que vivimos en la actualidad. Todo ello, determina no sólo diferentes estrategias en las relaciones entre los ámbitos de producción, recepción y consumo, sino también conexiones entre conceptos como original y copia que no se habían dado hasta hace relativamente poco. Lo que sigue es por tanto, una aproximación teórica a la necesaria reformulación de estándares monolíticos en el ámbito artístico, una crítica a la originalidad.

Palabras clave: Originalidad, copia, arte múltiple, hiperreproductibilidad 
a creación contemporánea es un ámbito complejo, en su variedad $\mathrm{y}$ heterogeneidad, que promueve una profunda revisión de los antiguos preceptos $\mathrm{y}$ procesos tradicionales ${ }^{1}$ que definieron $\mathrm{y}$ acotaron el ámbito artístico, pues inevitablemente los ha alterado.

\section{De la Situación Actual}

La posmodernidad -sea tomada como superación, ruptura, interrelación o continuación de estos postulados pretéritos- ha significado una revisión/ abandono de las fundamentaciones de la Ilustración y las diversas revoluciones, de los discursos de la Razón y la Ciencia, de las ideas de tecnología y progreso burguesas, para verse inmerso en diferentes crisis políticas, culturales e ideológicas, en un mundo "globalizado" pero de indiscutible introspección. Y estas molestias ontológicas, epistemológicas, procedimentales, etc., germinadas en los diferentes campos del saber, han provocado una necesaria autorreflexión disciplinaria. Un mirar-hacia-adentro que les obliga a admitir -y a considerarse en- la hibridación, el eclecticismo, el nomadismo teórico, la deconstrucción de los procesos, la libre mezcolanza de modelos clásicos y actuales, la repetición y reinterpretación de textos e imágenes, etc., como otras estrategias de aprehender el mundo sensible. Maniobras que confabulan, además, con las nuevas tecnologías de la información y comunicación para: por un lado, disponer escenarios temporales, fragmentarios, heterodoxos y diversificados que se enfrentan a la utopía moderna, y por otro, reflejar el aspecto plural y el alcance de los medios de comunicación de masas en un crecimiento exponencial de la cultura visual. De este modo, si el escenario nos lleva a experimentar una disolución de fronteras entre la realidad y su representación, debe acontecer también la descontextualización del concepto de original -y por tanto, también del proyecto de originalidad-, tradicionalmente ubicado en la cultura occidental. La insistencia de un "atributo axiológico" (Morales, 2000) de aspiración singularizante y promulgación de continuidad, no parece contemplar las fisuras recientes. De hecho, el acto mismo de este cuestionamiento se debe a una necesidad proveniente de las nuevas características y circunstancias del sistema en el que la originalidad estaba localizada: la autoría, la normatividad institucional, la conceptualización artística, la reproductibilidad técnica, la hiperindustrialización ${ }^{2}$ de la cultura 
(Cuadra, 2007), los museos, etc., aquellas estructuras en expansión -tendentes a la multiplicidad-que enfrentan/acompañan las viejas peroratas de oposición entre el original y la copia.

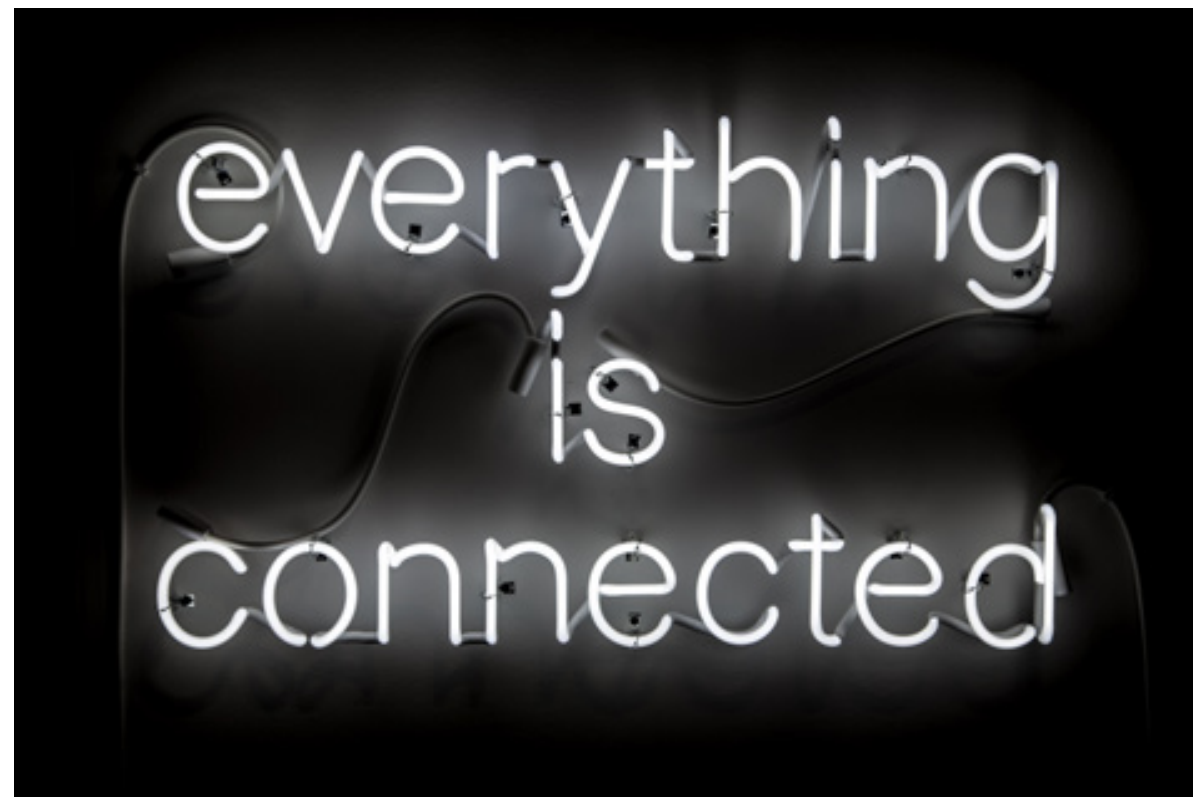

Figura 1. "Everything is connected" (2015) de Peter Liversidge, en The Armory Show 2015 siguiendo con la exploración ya iniciada en la Frieze Art Fair en Londres (2012-2014) en el Sculpture Park. Fotografía Creative Commons por Alex Berger (Nueva York, 7 marzo de 2015).

La idea de originalidad $u$ original suele ceñirse tanto a aquello diferente ideado, creado, inventado o producido -sea objeto o concepto-, a partir del cual pueden generarse una serie de discursos o entidades tomando el primero como patrón; como al de origen, aquel lugar del que emanan los demás, aquel horizonte en el que nacen las cosas. Al aproximarnos a la descripción enciclopédica del término, podremos comprobar que incluye otros tantos como inventiva, creatividad, autenticidad, novedad, modelo, singularidad, etc.; constructos que en el contexto anteriormente citado, permanecen imprecisos, en constante actualización dentro de la cultura, el pensamiento y la vida social ${ }^{3}$. De este modo, regresando a nuestro presente, hemos de ser conscientes de nuestras potencialidades, sobre todo cuando la hiperreproductibilidad digital 
puede reiterar hasta la infinitud cualquier objeto o teoría, cuando el productor no está separado del consumidor o el reproductor, sino que pueden ser la misma persona -desde la perspectiva del prosumidor $^{4}$-, o cuando la importancia ya no reside totalmente en los hechos, sino en sus interpretaciones (Vattimo et al, 1990). El relativismo cultural, la incorporación y establecimiento de posicionamientos estéticos alternativos reconfigurándose constantemente para aproximarse al conocimiento de lo sensible, no sólo produce una sensación melancólica -al pensar en la trasnochada unidad que nos caracterizaba-, también porta la esencia de una época altamente productiva, heterogénea y versátil para los campos de la creación: "La copia acerca la masa social a la realidad estética de su época y, en virtud de esta, se produce un radical cambio en las condiciones y valor expositivo de la obra, que pasa de la lejana distancia del culto aurático a la democrática proximidad participativa que proporciona el espectáculo de masas" (Martínez, 2011, p. 273) Desde esta perspectiva -e importando de Jameson (1991)- podríamos preguntarnos entonces ¿Cómo podemos pensar la originalidad en la superficialidad visual contemporánea dentro del nuevo subsuelo emocional del capitalismo multinacional?

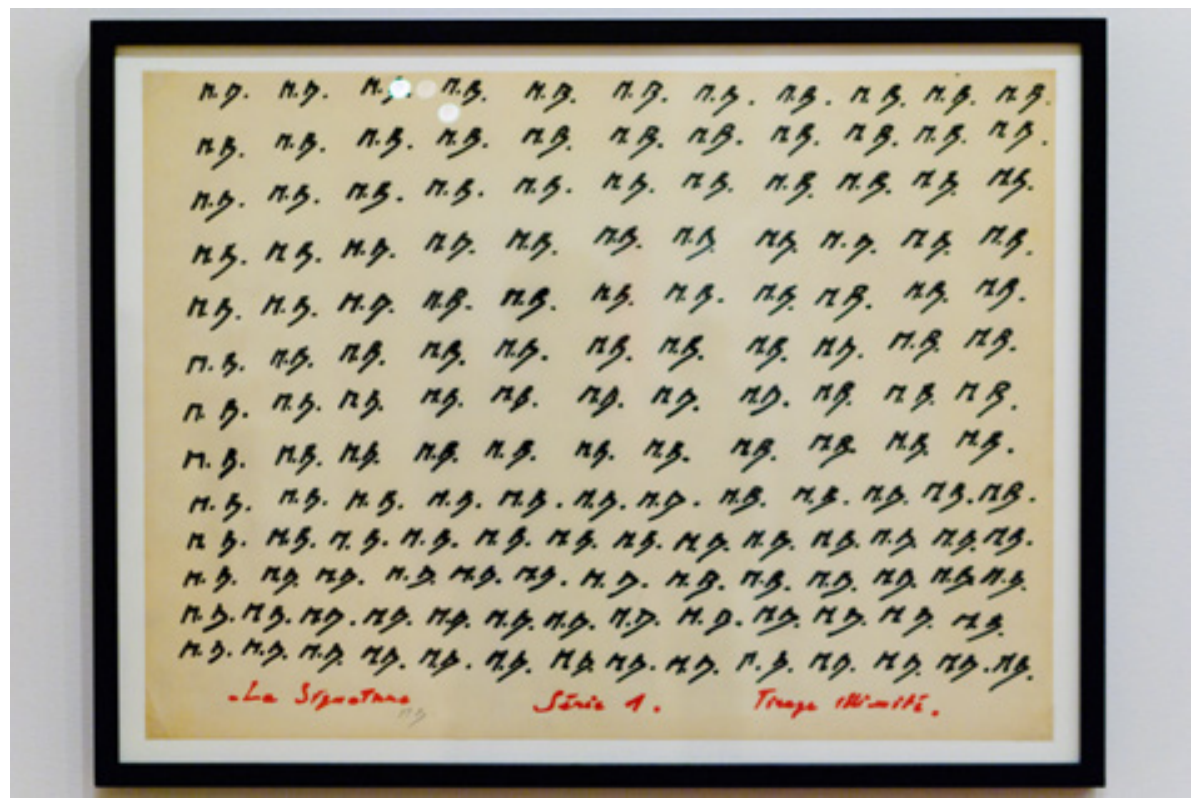

Figura 2. "La signature. Série I. Tirage illimité" (1969) serigrafía de Marcel Broodthaers. Fotografía Creative Commons por Derek Mead ( 6 de agosto de 2011). 


\section{De la Solidez de lo Original}

La cultura de la copia ${ }^{5}$ en la que vivimos es un desafío que nos reta a (re)pensar los conceptos que creíamos conocidos no sólo en los modelos educativos, la informática o la antropología, también en la creación artística, los estudios culturales o la estética. Acondiciona una serie de espacios para el pensamiento que apuestan por el encuentro, la intersección y la transversalidad de los saberes, pues la coexistencia originalidad-copia no es una relación exclusiva de ningún campo del conocimiento, es más, extiende su herencia a cualquier creación física e intangible dentro de los procesos socioculturales. Dentro de esta discusión en el arte, cohabitarían tanto las formas cosméticas de "embellecimiento" de la realidad, dentro de los esquemas económicos y reproductivos institucionalizados, como aquellas que pretenden transformar estos sistemas para dinamizar las legitimaciones establecidas y actualizarlas con nuevas estructuras comunicativas (Vásquez Rocca, 2007). Una reyerta que por considerarse polarizada fundamentaría sus razonamientos en la relación de enfrentamiento-convivencia de lo original y/con lo copiado dependiendo de las perspectivas e intereses del enfoque. Así, no sería tanto cuestión de salvar la distancia, por ejemplo, entre original y copia, sino de trabajarla para abrir una práctica consciente de sí misma cuya ofensiva sea transferirse como sistema en el que lo original sea un proceso hacia lo múltiple y viceversa, a través de lógicas que sirvan al control externo e interno de su naturaleza: "El arte múltiple es ahora un vasto escenario que -como ya apuntaba Stephen Bury (2001) - se resiste a ser definido. Es un ser simbionte, vive en relación, con las tecnologías, los materiales, con aquello reproducible, y por ende, prefiere existir en los límites de las posibilidades, habitarlos [...] En definitiva, lo rescatable, aquello que perdura, su devenir en adaptación es lo que ha sobrevivido a todas sus mutaciones. [...]Nuestra práctica artística se desliza hoy fácilmente por este territorio que posibilita la democratización de la obra artística, pasando de exhortar lo auténtico a exportar al arte a la vida cotidiana- ubicando a la obra de arte única como sospechosa-." (Mínguez y Méndez, 2014, p. 131). 


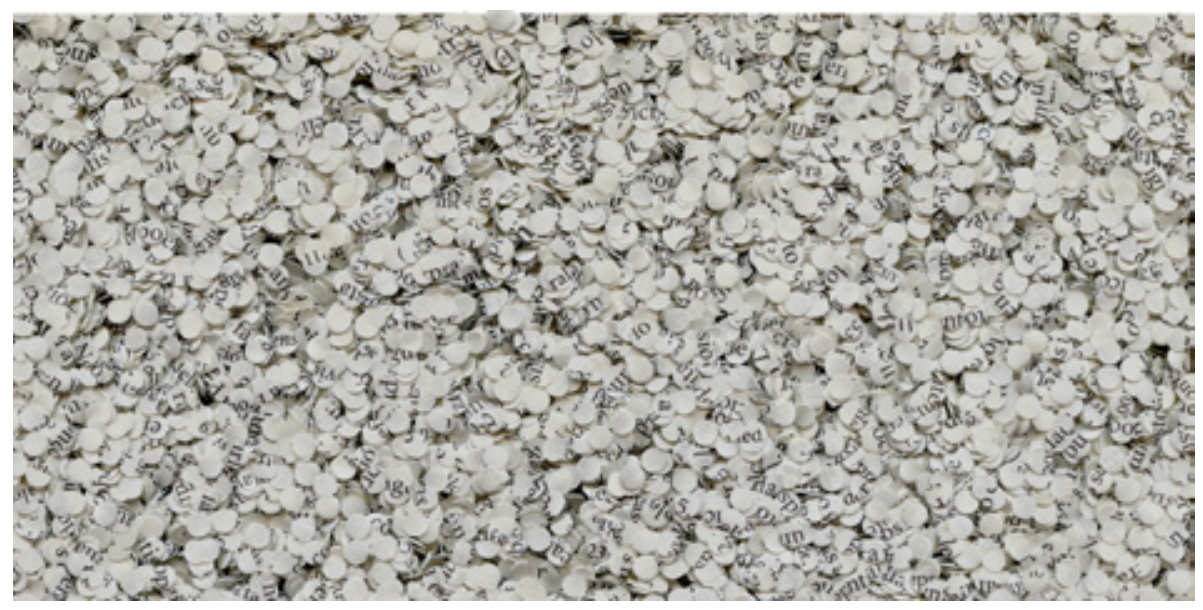

Figura 3. "Tractatus logico-philosophicus.Autor: LudwigWittgenstein (2003).Alianza Editorial S.A., Madrid. ISBN: 978-84-206-5570-3" (2013) Fotografía y metacrilato sobre aluminio, 120 × 380 × 3 cm., de Jesús Pastor. Imagen cortesía del artista.

Así, en este punto creo conveniente alejarse de la concepción de original como tasación - más cercana a disposiciones legales y jurídicas- para (re) vincularla a su presente con la complejidad y multiplicidad que merece, con sus correspondencias culturales y contextuales actuales, es decir, para enlazarla a su copia. Una tarea dificultada tanto por la descentralización actual del concepto en términos estético-artísticos, así como por la imposición, contagio y saturación de discursos manidos y clavados en su legitimación como criterio absoluto de valoración y juicio -más atribuido al surgimiento romántico-. Es por ello, que intentaré allanar el camino a partir de algunas preguntas, partiendo del cuestionamiento siguiente: ¿puede lo original seguir definiendo la autosuficiencia y la innovación incontestable en el plano artístico? Primero deberíamos admitir que la obra original ya no sólo ha de responder a las competencias dentro del atareado gremio artístico, sino someterse a las inclemencias del mercado (Hauser, 1973). Ya no sólo se identifica con la búsqueda de verdad y belleza, aquellas entidades que inmortalizaban al artista y eternizaban la obra, ahora ya no es "equivalente a una individualidad excepcionalmente creativa" (Morawski, 1977, p. 134). Hauser (1973) ya descartaba su asignación de juicio o validez, cuando aseguraba que no puede existir como criterio ya que del "arte apenas si se puede afirmarse nada, de lo cual no pudiera también afirmarse, en cierto aspecto, lo contrario" (p.425). Es 
decir, si el juego del arte se reinventa a cada instante ¿cabría entonces regla permanente que acote los límites de su práctica? Y en todo caso, ¿por qué resulta de interés? Podríamos pensar que precisamente en la pérdida de su heredada definición está la razón de su relevancia, es decir, en la necesidad de establecer sus dominios fuera de la imposición y el imperativo que ha defendido durante siglos. Replantear precisamente la búsqueda de la novedad en el enfrentamiento a la repetición o en el entumecimiento de su sentido de "diferencia", llevaría a quebrantar la hasta ahora indispensable unión entre la originalidad y la autenticidad, a abrir una explícita pugna dialéctica entre originalidad y tradición -entablada en estos términos en el momento en el que la originalidad total o absoluta no existiera-, comprendiendo conexiones históricas insalvables y rasgos convencionales para hacerla "comprensible": "Abordar la noción de "original", ya sea para criticarla o añorarla, parece de tránsito obligado, un fin en sí mismo. También aislar el carácter fenomenológico de esa copia-sin-original en que se constituye el simulacro, relacionado con el fin de la historia y la imagen en bucle eterno." (Marte, 2013)
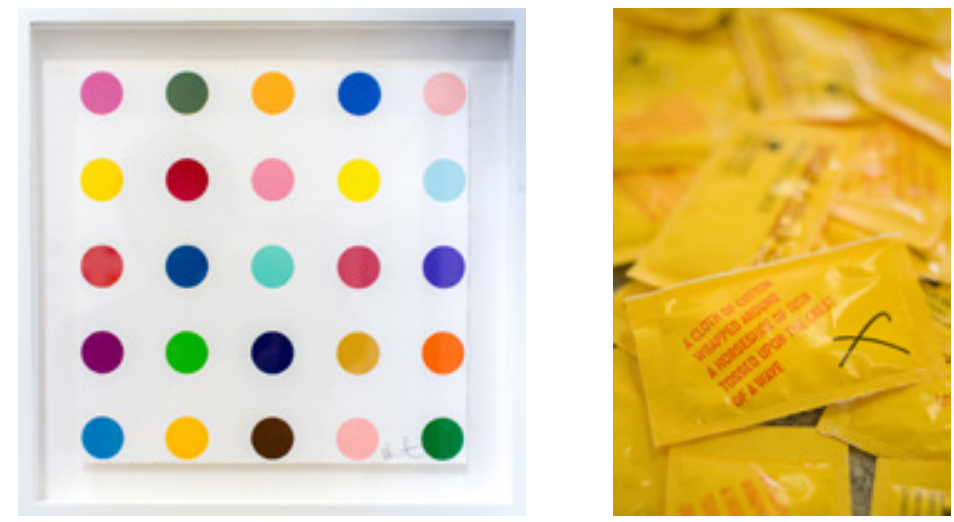

Figura 4. "The Crest of a Wave" (2008), escultura efímera de Lawrence Weiner. El 24 de septiembre de 2008 se distribuyeron 300.000 sobres de azúcar impresos con su "statement" A cloth of cotton wrapped around a horseshoe of iron tossed upon the crest of a wave, como parte del proyecto homónimo dividido en 4 partes (una escultura efímera, una instalación, una pieza musical y una acción) para la Fundació Suñol de Barcelona. Fotografía Creative Commons por Pierre-Jean Moulis (Barcelona, 8 de octubre de 2008).

Figura 5. "Thr-ser, 2012 (1-inch woodcut spot)" (2013), edición limitada de estampas de Damien Hirst, en Art Basel Hong Kong 2013. Fotografía Creative Commons por See-ming Lee (23 de mayo de 2013). 
Exige la revisión de ese síntoma, la misma pérdida de pureza que implica(ba) lo auténtico, sabiendo que en el eclecticismo actual en los territorios del arte -con sus preocupaciones y ocupaciones-, no hay incontaminados. Convencionalismos contra los que la originalidad se posiciona en la actualidad, sabiendo al mismo tiempo que, hasta el momento, sólo ha sido válida en ellos: "Quizás se precise investigar hasta qué punto, como criterio de validez general para el arte, a la originalidad tributarían otras cualidades o particularidades no vistas del fenómeno artístico, o hasta qué punto la originalidad no constituye para la axiología del arte la cualidad básica por excelencia para el juicio de valor" (Moya, julio-septiembre 2001, p. 101). Sea como aspiración, tendencia o cualidad, la originalidad está dialécticamente unida a su contrario: la tradición. Por lo que el interés no sólo se ubica en esa posición de individuación extrema como nueva presencia en el mundo, sino también en que esa singularidad, ese epicentro, se descubre por los intercambios de universalidad, por ese anclaje al origen que le identifica con su humanidad.

Pero entonces, en un contexto de masificación y consumo apresurado de las creaciones y una altísima capacidad de reproducción y distribución de las cosas - hasta podría decir que desmedidamente- ¿dónde queda el imperio de la originalidad? ¿Qué validez tiene actualmente? Está claro que la respuesta no puede obviar toda la plataforma programática que se ha configurado alrededor del concepto, condicionada por elementos socioculturales e ideológicos y la capacidad mutable y dinámica de éstos. La originalidad, hoy en día, ha de considerar lo permutable, así como las formulaciones extra y paraestéticas, pues parece que ubicarse en el habitual acto excepcional, en la singularidad independiente o en el discurso causa-efecto, proporciona cierto reduccionismo e insuficiencia para legitimarse: transformarse en un íntimo compromiso ideoestético con su tiempo (Morales, 2000). Pues lo único, lo singular, indica "que ese objeto existe, que es real" (Rosset, 2007, p.43), que con él aparece la creación, pero no asegura categóricamente el florecimiento de lo original. Desde este punto de vista, ¿se podría visionar la originalidad como utopía? No sería una consideración desdeñable, quizás hasta deseable desde estas incertidumbres contemporáneas que la incluyen a la vez como distinción de lo repetido- y como vocación de mejoramiento - pues la originalidad incluye semantemas de futuro-: "El concepto de originalidad, que es el de lo originario, implica tanto lo muy antiguo como lo que no ha existido todavía, es la huella de lo utópico en las obras." (Adorno, 1970, p. 227) Pareciera que entre originalidad y utopía se encontraran los ideales estéticos (Sánchez 
Vázquez, 1996), pues de su colisión no sólo implica ruptura, sino como vemos, también continuidad y porvenir en su presente -voluntad de crear lo que todavía no existe-, la llamada "religión de novedad" de Compagnon (1993). "La utopía no sólo tiene una existencia ideal, sino también real, por su capacidad de inspirar el comportamiento práctico de individuos o grupos sociales produciendo efectos reales, en la realidad presente. La utopía, como práctica, sin dejar de ser tal, al no ser absorbida nunca por la realidad, es también topia: se hace presente en algún lugar" (Sánchez Vásquez, 1996, p. 112).
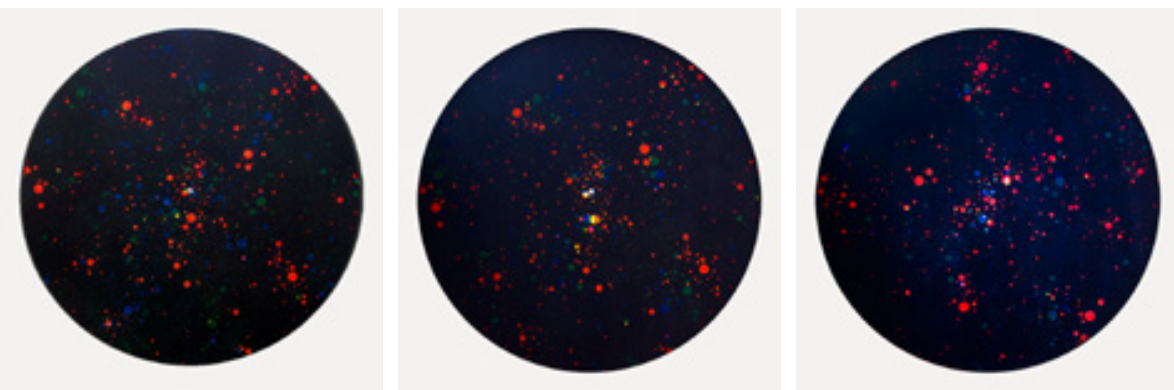

Figura 6-8. "Eón" (2012-2013), serie de linóleos de Rubén M. Riera. Figura 6: 5h31'38"; Figura 7: 6h37'39"; Figura 8: 7h34'00". Serie de 3 estampas, de 3 colores (RGB) cada una, que traduce el tiempo transcurrido en diversos recorridos a una visualización cromática, por lo que los pigmentos representan los datos temporales registrados. Imágenes cortesía del artista.

Aunque habría que considerar lo siguiente: que haya utopía no supone la existencia de originalidad, sino la del involucramiento de su búsqueda. Por lo que podríamos suponer: ¿Será la originalidad una especie en extinción dentro del mundo artístico? Efectivamente, puede seguir alimentándose un discurso estético agotado y sumido en la tradicionalidad y formalización, incapaz de reaccionar ante la pluralidad, la efimeridad y movilidad de la creación, del conceptualismo, de las interdependencias y las esterilidades funcionales. Pero ese tipo de originalidad, basada en cánones, sacralizaciones 
y absolutos perennes, se ha perdido en su centro gravitatorio; la creación se ha descentrado, orillado a los márgenes mediante deslizamientos estéticos, las intertextualidades y las implementaciones efímeras. Por lo que lo original, en su voluntad de superar esta crisis de autonomía, persigue ahora lo promiscuo, la corrupción de citas -en apropiaciones, remixes, homenajes, revisitaciones, etc.-, la reconstrucción continua de "lo antiguo", para obtener un significado ubicado en su tiempo, en el pensamiento bricoleur. Es decir, posibilita un siendo-en-la-repetición, en contraste con el siendo-único-frentea-todo, donde la variación es posible sin certezas, distorsionándose la imagen cultural fija, pues actualmente no puede representarse de una única manera. La repetición es una estrategia delicada en la que reside el centro neurálgico de la discusión actual. Pero no hablo de iteraciones simplistas, populistas o de la sobreidentificación gratuita del original (Grzinić, 2008), sino del carácter múltiple del mundo y de sus estrategias para comprenderlo, que van más allá de la polarización de lo auténtico y lo inauténtico. Hasta cierto punto, podría considerar la batalla entre original y copia en el recuerdo constante de los deseos de dominación inyectados por el pasado, en la lucha por la sumisión del otro. Pero como vemos, si seguimos anclados en ese enfoque, será una cruzada sin consumación posible: la copia, con evidente superioridad numérica siempre ha de reflejarse en un original, que a su vez se ve frustrado al no ser, por sí mismo -sin la copia-, objeto de deseo. Es posible que atestigüemos el imperio de la copia, pero lo hacemos sobre las leyes del original, por lo que no podremos afirmar tampoco la agonía de ninguno ${ }^{6}-$ ni tampoco su total determinación-, al estar inmersos en un complejo sistema económico que se sirve tanto del impulso de lo irrepetible y su heterogeneidad, como de la más despótica maquinaria de reproducción y homogeneización para aumentar el deseo -y mantenerlo-. Una estructura que vende la inmortalidad de lo que siempre-ha-sido originalidad con la efervescencia de lo transitorio: Una única verdad con copia para todos. Por ello, la política del enfrentamiento y la economía del beneficio no podrán concluir con esta diatriba estética más allá de sí mismos. ¿Pero se trataría entonces de desertar de esa imposición de "uniformidad" - condición negadora, devastadora de cualquier sentido de originalidad-, para admitir la inconveniencia -para el prosumidor actual- de la unicidad irrepetible de la obra y su intento por eternizarse? 

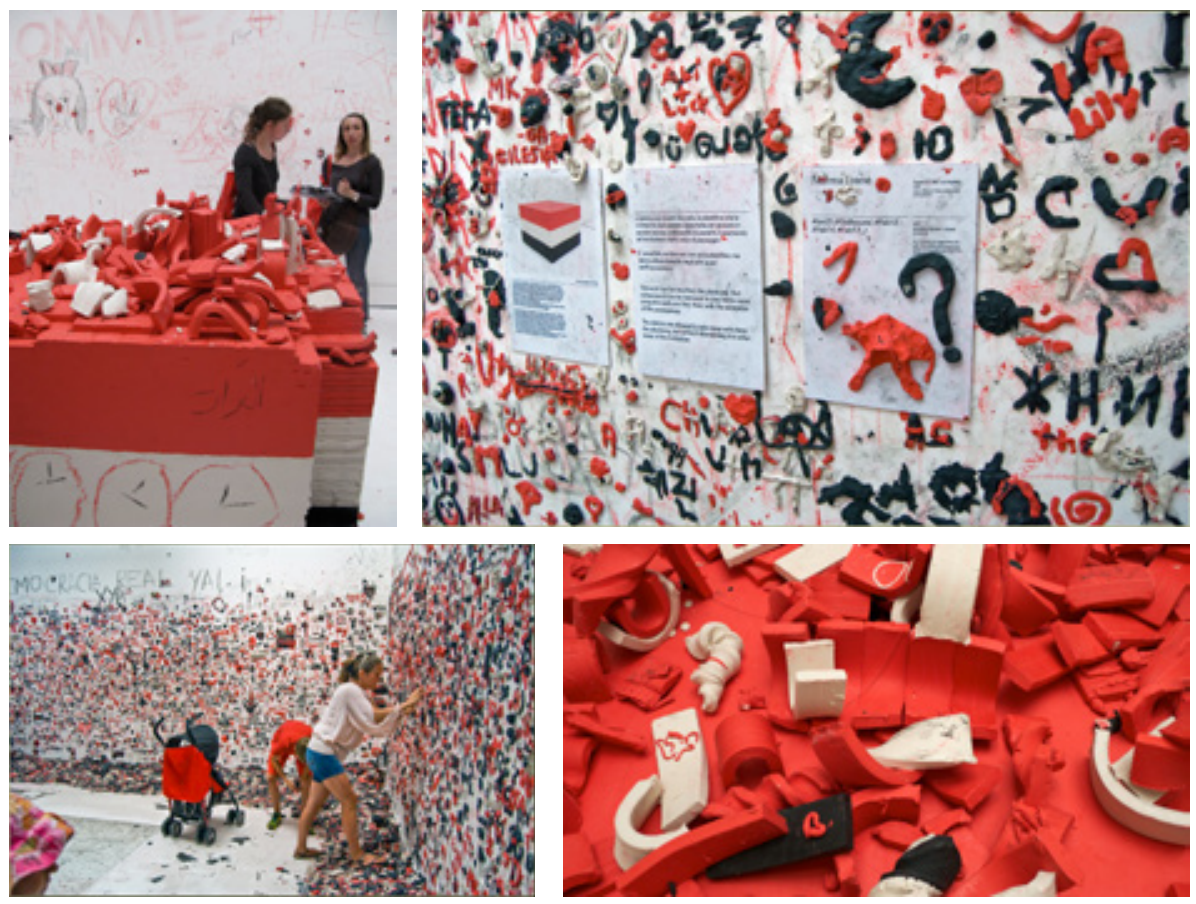

Figura 9-12. “\#Jan25 (\#Sidibouzid, \#Feb12, \#Feb14, \#Feb17...)” (2011), instalación con plastilina de Norma Jeane. Partiendo de un cubo tricolor de plastilina perfectamente tallado, la acción de los espectadores durante la Bienal de Venecia 2011 se apodera de la habitación de una forma caótica. Fotografías en Creative Commons: fig. 9 por Latitudes; Figs. 10 y 11 por Marie Jirousek; Fig. 12 por Willem Velthoven.

Si lo original anteriormente resistía a su época y geografía para manifestarse a través del tiempo como ícono de deseo y permanencia en el arte, ahora, en alguna de sus formas, trasciende el anonimato (impersonal) para ser, aunque momentáneamente, un acto efímero en boca de todos. Y es que la originalidad actual encaja perfectamente en el pliegue que se produce entre lo perpetuo y lo pasajero, ya que no responde con absolutos ni tribulaciones precisas, vive en el límite del deseo y su consumo. Si la sociedad contemporánea considera que el "viajar esperanzado es mejor que llegar" a cualquier meta en un mundo donde "nuestro deseo no desea satisfacción, desea seguir deseando" (Bauman, 2007, p.19), es lógico que la "satisfacción completa" -aquella que ofrece la 
vieja originalidad- pueda considerarse intimidatoria. Cuando experimentar las sensaciones ha sustituido las cosas concluyentes, esa asociación antiquísima de la originalidad como congelación del tiempo se diluye en el "necesario" consumo -y por tanto, degradación- del objeto, que se manifiesta más "como suceso artístico que como perennidad" (Morales, 2000, p. 10). Un objeto inquieto, cambiante y metamorfo que intenta, por un lado, asirse a su vínculo con lo invariable e imperecedero, y por otro, desea compensarse con la mortalidad de la cotidianidad. Es un objeto que aspira a la paradoja, a resistirse, por un lado, a un universo contemporáneo que subsiste del ocaso, a la vez que por otro, se deja llevar por esta obsolescencia para obtener el máximo impacto que ofrece una singularidad perecedera. Si en la actualidad, la originalidad -o su búsqueda-se activa en lo fragmentario, múltiple y efímero, la permanencia de su deseo exige el abandono de la eternidad que había ostentado, y que aquello excepcional no sea su atemporalidad, sino precisamente lo perecedero de su acontecimiento. $\mathrm{Si}$ "nada distingue el trato que reciben los objetos de arte: comparten la misma suerte que todas las otras cosas que amueblan nuestro mundo vital, nuestro Lebenswelt" (Bauman, 2007, p.22), será requisito enfocar también su idea de originalidad en esta realidad múltiple y fugaz.

\section{A Modo de Cierre}

Durante mucho tiempo se ha alimentado una naturaleza artística custodiada "por la nominosa lejanía de la obra única", cercenando por tanto, la relevancia de aquella reproducible y múltiple, pues hasta hace poco su hábitat no "visionaba aún que aquella apuesta por la reproductibilidad no iba a residir en el valor económico de la copia, sino en el poético." (Mínguez y Méndez, 2014, p.130). Sin embargo -y más allá de lo que anunciaba Benjamin-, ahora la copia resurge victoriosa. El arte múltiple ha superado esta devaluación para posicionarse con mayor rotundidad argumentativa-como lenguaje representativo de nuestra época, reelaborándose y extendiéndose en su ser-múltiple desde lo complejo y la hibridez, borrando las fronteras y viviendo en ese pliegue de lo pasajero y lo perpetuo que comentaba. Estamos siendo testigos del salto en el que nos desplazamos de la idea demeritada de la copia para aterrizar en la de la copia como pensamiento y proposición poética, como forma de creación. "Desde la propia configuración formal de la obra, esto es, su epidermis codificada, pasando por su imbricación seriada o modulada en conjuntos instalativos, hasta su introducción y su validación en el sistema cultural y de mercado, 
tienen hoy en el paradigma de lo múltiple un esencial factor rector de fondo" (Martínez Moro, 2011, p. 274). Ya no es problema la reproducción limitada o ilimitada, pues la cantidad en un mundo tecnológicamente ubicuo resulta algo irrelevante. La repetición es ya una concreción de práctica artística, y con ella llega la permisibilidad de las variaciones -huir de la homogeneización-: podemos tomar el objeto como matriz y modelo de lo que sigue o tomar precisamente la serie como cimentación para la generación de piezas, incluso entender la yuxtaposición y el palimpsesto como estructura primigenia del pensamiento para la creación. La copia ya no es la superficie, es una estructura dialógica que funciona como medio y herramienta, que hace germinar una epistemología del arte siendo-múltiple, siendo-en-ejecución (work in progress) o imperfecto: "En la actualidad, y más allá de las necesidades del mercado, no se debe equiparar el valor del objeto artístico con su unicidad, especialmente cuando hablamos de técnicas artísticas que permiten elaborar ediciones. Es necesario por tanto considerar como factor añadido la capacidad de reproducción de una obra de arte realizada mediante estas herramientas, más incluso si la repetición forma parte de la misma obra, donde la multiplicidad ayuda a construir el discurso." (Martín-Jiménez, 2010, p.7). 

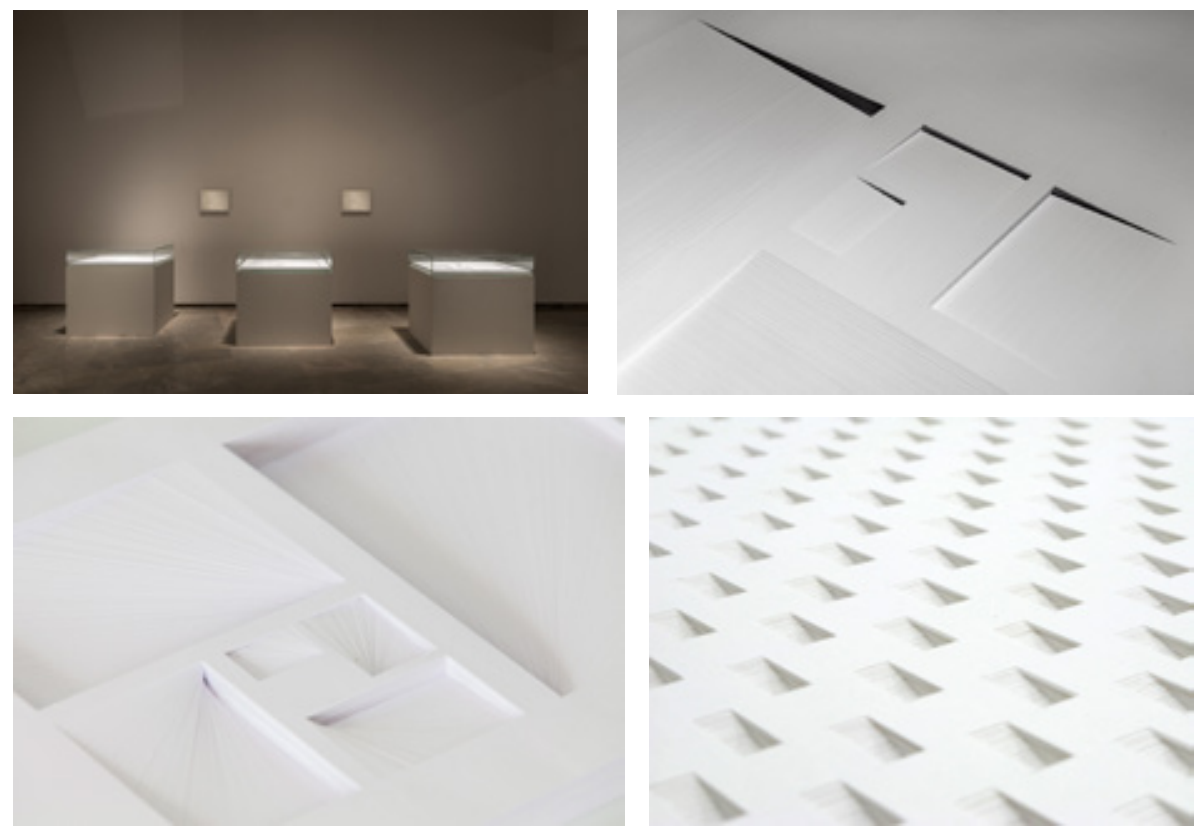

Figura 13. "Mil.límetre / Gurnia Fibonacci" (2013), papel cortado a mano de Manuel Blázquez. Visión frontal de la pieza en la exposición Trazas (2014), en el Centro del Carmen de Valencia (España).

Figuras 14-15. "Mil.límetre / Gurnia Fibonacci” (detalles, 2013) de Manuel Blázquez. Figura 16. "MM OPUS. Quadratum I” (detalle, 2014), de Manuel Blázquez. Imágenes cedidas por el artista.

Es difícil conservar hoy la ida de la solidez artística que permitía el proyecto de originalidad de otras épocas, más cuando el "capitalismo ha permitido al arte entrar en la vida cotidiana y liberarse de su encierro en museos" (Lipovetsky, 2015). Cuando imaginamos la conocida frase: "Todo lo sólido se desvanece en el aire", no sólo hemos de atender a su potencia dramática o a su voluntaria ambigüedad, también a esa pérdida del centro, a la ingravidez de las cosas -así como a la descentralización del sujeto-, a su entretejimiento global, totalmente en relación. Así, el arte se ha insertado en nuestro día a día, y esta estetización de lo diario provoca un mundo "exageradamente bello" siguiendo la premisa de Michaud (2007, p.9) - que tanto se libera de los museos como comercializa con la belleza y las emociones. Estamos en un momento 
en el que realidad y ficción se intercontaminan, generan una serie de tensiones de intercambio que caracterizan el comercio y consumo de textos visuales o escritos, y a través de sus porosidades, transitan las riquezas semánticas de nuevos pensamientos culturales (Martínez, 2012). Las ideas se infectan entre sí ante una realidad que sólo puede que expandirse, elaborar nuevos campos de sentido que fluctúan entre las más complejas abstracciones conceptuales hasta las más accesibles estrategias de lo cotidiano. Así la cultura forma parte de un complejo engranaje mercantil -aunque siempre ha sido negocio en uno $\mathrm{u}$ otro aspecto- que determina la ubicación de la copia en lo original y lo original en la copia en un vasto escenario de potencialidades creativas, pues recordemos que esta "motivación económica no mata la creación, [sino más bien] la democratiza" (Lipovetsky, 2015). Capacita una desjerarquización de la cultura cuya democratización de la idea de originalidad, precisamente en la actualidad, parece residir en la repetición, en la relectura, en la instantaneidad, en el consumo y su deseo, un concepto que se extiende a otro estado de las cosas, donde lo eterno es la idea -aislada de la fugacidad-y las realizaciones, los objetos, son meras manifestaciones pasajeras que permiten pasiones fugaces.

Si hoy en día, nos cuesta trabajo -en este sentido-diferenciar apreciaciones estéticas e ideológicas viables y visibles entre una tienda de modas, una feria de comics y una galería de arte, no deberíamos pretender que la idea heredada de originalidad cubra requisitos innecesarios -extra-estéticos o extra-temporales, al menos- en nuestra cultura actual, sino más bien, intentar mitigar esa posición dual -original vs copia-, para poder dilucidar las resoluciones que como proyecto complementario y entrelazado abarcaría. Quizás la copia no baste hasta sentirla original, y tal vez el original no sea suficiente hasta poder "consumir" su copia, posiblemente el problema siga latente hasta decidir si trazar/mantener demarcaciones entre uno y otra -asegurando la norma- o borrar aquellas que desde otros lugares implantamos -y apostar a ciegas-. 


\section{Carles Méndez - De la originalidad}

\section{Notas}

${ }^{1}$ Aquellas normas o directrices que entraban a consideración como la unidad, equilibrio, contraste, proporción y movimiento según patrones estandarizados, basados, en la mayoría de ocasiones en principios de mimetismo o naturalización de la representación. Evidentemente y salvando distancias, se podría reducir que su expresión cultural más marcada fue la alcanzada por la Ilustración y el régimen ojocentrista.

${ }_{2}^{2}$ Muchas han sido las visitas a Benjamin y la reproductibilidad técnica de la obra de arte, hoy en día sabemos de las amplias posibilidades en este aspecto, que nos permiten transitar de la autoedición a la hiperreproducción con un botón. Retomando las ideas de Benjamin y el término acuñado por Adorno -industria cultural como producción, distribución y consumo de bienes simbólicos-, junto al concepto de hiperreproducibilidad de Stiegler, que incorpora la capacidad de diseminación tecnológica en las prácticas sociales, Alvaro Cuadra (2007) propone la Hiperindustria cultural en consideración de las, ya no tan nuevas, tecnologías de la información y comunicación para el establecimiento de nuevos "regímenes de significación" y construcción del presente (como historia, como relato y como fenómeno). De este modo, se transforma, no sólo nuestro modo de pensar, sino también nuestras formas de percibir nuestro entorno y nuestra existencia en él.

3 Únicamente clasificables dentro de períodos históricos, momentos artísticos o insertos en ciertas actitudes filosóficas, y envueltos en el dinamismo que la descentralización de la autoridad intelectual y científica propicia.

${ }^{4}$ Partiendo de la idea de simultaneidad en el consumo y la producción posibilitada en el mismo individuo de McLuhan en los años 70, Alvin Toffler desarrolla el término "prosumidor" en su libro La tercera ola (1980) para predecir los procesos de mercado de "personalización en masa" y la involucración de los consumidores en la producción, descentralizando los antiguos cánones de emisión de los bienes culturales.

${ }^{5}$ La "cultura de la copia", tomada como lugar de origen y partida de este texto, puede entenderse tanto desde el punto de vista de la fascinación "fetichista"-sobre todo en el plano occidental-de reiteración, de replicar, de duplicar e incluso falsificar nuestros productos culturales (materiales o inmateriales) (por ejemplo en Schwartz, 1996 o Dorfles, 2010), como también y sobre todo, el escenario que sustenta la hiperreproductibilidad técnica y la digitalización omnipresente, donde creador y receptor se entremezclan para formar parte de nuevas formas de producción simbólica y poéticas que remezclan, remasterizan, revisionan, rehacen, revisitan y alteran en diversas aproximaciones conceptuales y morfológicas.

${ }^{6}$ Marina Grzinić (2008), a este respecto, sostiene que "La copia es dueña de la situación [...] La copia tiene un exceso de conocimiento que puede resumirse en esta frase "La copia contienen la idea de original y también contiene su propio concepto". La copia nos dice "estoy disfrutando esto", cosa que no puede decirse del original, ya que no es capaz de tal disfrute. El original está de hecho sometido a varias leyes: las del mercado del arte, de las tendencias, de la historia, de la Bolsa, etcétera. Por eso la copia puede dejar al descubierto cuestiones éticas, políticas y pedagógicas que van más allá de la relación entre el amo (la ley) y la víctima (el original). La copia no tiene sentido; el original es víctima de las normas y genealogías capitalistas asentadas en el mercado del arte y verificadas en la Bolsa. ¿Sufre el original? ¡Ya lo creo! Pero de hecho no está al corriente de su propia ignorancia. La copia se aprovecha de esa ignorancia, produciendo un exceso de disfrute y una radicalización del original y de su propia posición" (pp.156-157). Aunque en este sentido, y como recalco en el texto, puede resultar engañoso, artísticamente hablando, situar a original o copia como vencedores o vencidos dentro de una situación más abstracta $-\mathrm{y}$ profundamente más política- como el sistema cultural (occidental) y económico (neoliberal) sobre el que ambos términos están cimentados. 


\section{Referencias}

Adorno, T. W. (1970). Teoría estética. Madrid: Taurus.

Bauman, Z. (2007). Arte, ¿líquido? Madrid: Sequitur.

Bury, S. (2001). Artists' multiples, 1935-2000. Aldeshot: Ashgate.

Compagnon, A. (1993). Las cinco paradojas de la modernidad. Caracas:

Monte Ávila.

Cuadra, A. (2007). Hiperindustria cultural. Disponible en línea en la dirección: http://www.oei.es/salactsi/HIPEBOOK.pdf

Dorfles, G (2010). Falsificaciones y fetiches. La adulteración en el arte y la sociedad. Madrid: Sequitur.

Grzinić, M. (2008). Procesos de encarnación en fronteras: Tanja Ostojić y la diferencia mínima. En Zehar. Revista de Arteleku-ko aldizkaria, n ${ }^{\circ} 64$ (pp. 148-159). Disponible en http://blogs.arteleku.net/zehar/wp-content/ uploads/2009/01/grzinic_en_es.pdf

Hauser, A. (1973). Introducción a la historia del Arte. Madrid: Guadarrama. Jameson, F. (1991). El posmodernismo o la lógica cultural del capitalismo avanzado. Barcelona: Paidós.

Lipovetsky,G. (2015). "La gente común no halla ya la felicidad en el súper, por eso escribe o hace fotos", en El Mundo, 25 de febrero, Crónica.

Disponible en línea en la dirección: http://www.elmundo.es/cronica/201 5/01/25/54c39959e2704e8d4c8b457c.html

Marte, P. (2013). El problema está en el medio. Bilbao: HPC

Consoni. Disponible en línea en: http://www.pablomarte.com/ elproblemaestaenelmedio.pdf

Martínez Moro, J. (2011). Crítica de la razón plástica. Método y materialidad en el arte moderno y contemporáneo. Gijón: Trea.

Martínez, J. (2012). Ensayo Z. Una antropología de la carne perecedera. Berenice.

Martín-Jiménez, J. (2010). Reproducción, repetición y reivindicación. Multiplicidad en el arte emergente español / Reproduction, Repetition and Rebellion. Multiplicity in Spanish Emerging Art.Madrid: Hablar en arte.

Michaud, Y. (2007). El arte en estado gaseoso. Ensayo sobre el triunfo de la estética. México D.F.: Fondo de Cultura Económica

Mínguez, H.; Méndez, C. (2014). "Territorio gráfico. De la serie y la memoria". Trazas. Valencia: Consorci de Museus de la Comunitat 
Valenciana.

Morales, E. (abril-junio 2000). Insuficiencias estéticas de la idea de originalidad. Islas (124), 3-11.

Morawski, S. (1977). Fundamentos de estética. Barcelona: Península.

Moya Méndez, M. (julio-septiembre 2001). "La originalidad en el arte.

Aproximación al concepto de Hauser". Islas (129) , 95-101.

Rosset, C. (2007). El objeto singular. Madrid: Sextopiso.

Sánchez Vásquez, A. (1996). "La utopía del fin de la utopía”. En Marx Ahora, 105-119.

Schwartz, H. (1996). La cultura de la copia. Parecidos sorprendentes, facsímiles insólitos. Valencia: Cátedra.

Vásquez Rocca, A. (2007). "Posmodernidad, deconstrucción y pensamiento postmetafisico". Psikeba. Revista de Psicoanálisis y Estudios

Culturales. Buenos Aires: en línea. http:/www.psikeba.com.ar/articulos/ AVRpostmodernidad-postmetafisico.htm

Vattimo, G., Mardones, J. M., \& Urdanabia, I. e. (1990). En torno a la posmodernidad. Barcelona: Anthropos. 


\section{Anexo}

\section{Índice de Figuras}

Figura 1. "Everything is connected" (2015) de Peter Liversidge, en The Armory Show 2015 siguiendo con la exploración ya iniciada en la Frieze Art Fair en Londres (2012-2014) en el Sculpture Park. Fotografia Creative Commons por Alex Berger (Nueva York, 7 marzo de 2015), disponible desde: https://www.flickr.com/photos/alexbergerr/16774744312

Figura 2. "La signature. Série I. Tirage illimité" (1969) serigrafía de Marcel Broodthaers. Fotografía Creative Commons por Derek Mead ( 6 de agosto de 2011), disponible desde: https://www.flickr.com/photos/ derekmead/6082020675/in/photolist-aguGZy-agrWRr

Figura 3. "Tractatus logico-philosophicus.Autor: LudwigWittgenstein (2003). Alianza Editorial S.A., Madrid. ISBN: 978-84-206-5570-3" (2013) Fotografía y metacrilato sobre aluminio, 120 x $380 \times 3 \mathrm{~cm}$., de Jesús Pastor. Imagen cortesía Jesús Pastor.

Figura 4. "The Crest of a Wave" (2008), escultura efímera de Lawrence Weiner. El 24 de septiembre de 2008 se distribuyeron 300.000 sobres de azúcar impresos con su "statement" sugar packets printed with the statement $A$ cloth of cotton wrapped around a horseshoe of iron tossed upon the crest of a wave, como parte del proyecto homónimo dividido en 4 partes (una escultura efímera, una instalación, una pieza musical y una acción) para la Fundació Suñol de Barcelona. Fotografía Creative Commons por Pierre-Jean Moulis (Barcelona, 8 de octubre de 2008), disponible desde: https://www.flickr.com/ photos/lttds/18967090798.

Figura 5. "Thr-ser, 2012 (1-inch woodcut spot)" (2013), edición limitada de estampas de Damien Hirst, en Art Basel Hong Kong 2013. Fotografía Creative Commons por See-ming Lee (23 de mayo de 2013), disponible desde: https:// www.flickr.com/photos/seeminglee/8864290568/in/photolist-eviNL1

Figuras 6-8. "Eón" (2012-2013), serie de linóleos de Rubén M. Riera. Figura 6: 5h31'38"; Figura 7: 6h37'39"; Figura 8: 7h34'00". Imágenes cortesía Rubén M. Riera. Más información acerca de estas piezas en su página web: http://www.rubenmriera.com/EON-1

Figuras 9-12. "\#Jan25 (\#Sidibouzid, \#Feb12, \#Feb14, \#Feb17...)" (2011), instalación con plastilina de Norma Jeane. Partiendo de un cubo tricolor de plastilina perfectamente tallado, la acción de los espectadores durante la Bienal de Venecia 2011 se apodera de la habitación de una forma caótica. 
Fotografías en Creative Commons: fig. 9 por Latitudes (Venecia, 1 de junio de 2011), disponible desde https:/www.flickr.com/photos/lttds; Fig. 10 por Marie Jirousek (Venecia, 18 agosto 2011), disponible desde: https://www. flickr.com/photos/mariejirousek/6055787962/in/photolist-ae5FJr-ae5FWXae8v7N-ae8v1m-ae8uMh-ae5FBk-ae8vKo-ae5GGp; Figura 11 por Marie Jirousek (Venecia, 18 de agosto de 2011), disponible desde: https://www. flickr.com/photos/mariejirousek/6055240191/in/photolist-ae5FJr-ae5FWXae8v7N-ae8v1m-ae8uMh-ae5FBk-ae8vKo-ae5GGp; Figura 12 por Willem Velthoven (Venecia, 1 de junio de 2011), disponible desde: https://www.flickr. com/photos/willemvelthoven/8709834354/in/photolist-egEbrw-egEbBSegEbiQ-egyqX4.

Figura 13. "Mil.límetre / Gurnia Fibonacci" (2013), papel cortado a mano de Manuel Blázquez. Visión frontal de la pieza en la exposición Trazas (2014), en el Centro del Carmen de Valencia (España). Figuras 14-15. "Mil.límetre / Gurnia Fibonacci” (detalles, 2013) de Manuel Blázquez. Figura 16. "MM OPUS. Quadratum I” (detalle, 2014), de Manuel Blázquez. Imágenes cedidas por Manuel Blázquez. Más información disponible desde su página web: http://blazquezmanuel.com/

Carles Méndez Llopis: Profesor titular de la Universidad Autónoma de Ciudad Juárez (UACJ), adscrito al Departamento de Diseño en el Instituto de Arquitectura Diseño y Arte (IADA).

Contact Address: Jefatura del Departamento de Diseño. Instituto de Arquitectura Diseño y Arte. Universidad Autónoma de Ciudad Juárez Av. Del Charro, 450 norte. CP. 32310. Ciudad Juárez (Chihuahua). México.

E-mail address: cmendezllopis@gmail.com 